\title{
Artigos
}

\author{
Luciana Maria de Aragão Ballestrin \\ Universidade Federal de Pelotas, Pelotas, RS, Brasil
}

\section{Feminismos Subalternos}

\begin{abstract}
Resumo: Especialmente a partir dos anos 1980, o encontro entre pós-colonialismo e feminismo trouxe importantes consequências práticas e teóricas para o entendimento da vida das mulheres sob o impacto - passado ou presente - do colonialismo. Uma das mais evidentes foi a geopolitização do debate feminista, inaugurado pela ideia de um feminismo terceiro-mundista e pós-colonial e que, atualmente, pode ser observado na tentativa de projetar um feminismo do sul e decolonial. O presente artigo possui dois objetivos teóricos principais: (a) demonstrar o antagonismo construído desde os anos 1980 entre o feminismo não ocidental e ocidental e (b) desenvolver um diálogo crítico com a versão contemporânea do feminismo decolonial latinoamericano em relação à noção de colonialidade de gênero. Proponho a noção de "feminismos subalternos" para a compreensão de um movimento paradoxal: a construção dos feminismos outros só é possível quando eles se subalternizam em relação ao próprio feminismo moderno. Como consequência, evidencia-se a tensão entre o limite da fragmentação de diferenças irreconciliáveis e a necessária cosmopolitização da agenda feminista.
\end{abstract}

Palavras-chave: Feminismo pós-colonial; feminismo descolonial; colonialidade; gênero

\section{Introdução}

Uma das constatações mais importantes realizadas nas últimas décadas no âmbito global da produção do conhecimento é a verificação da economia política que a estimula, particularmente no domínio das Ciências Sociais. Diferentes autores/as sustentam a existência de uma divisão global do trabalho que reproduz a lógica da geopolítica colonial e neoliberal: é do Norte global onde a criação de teorias com pretensões universais e explicativas são exportadas, estimulando um complexo processo de dependência acadêmica (Syed Farid AIATAS, 2003; Raewyn CONNELL, 2007). Com suas origens observadas desde o próprio nascimento das Ciências Sociais em termos de constituição, institucionalização e disciplinamento, observa-se, nos últimos anos, a articulação de um movimento acadêmico e intelectual que reúne diferentes perspectivas contestatórias a esse padrão em âmbito global.

Suas primeiras expressões mais dispersas e esparsas, por sua vez, podem ser rastreadas em diferentes contextos ao longo do século XX. É mais recentemente, contudo,

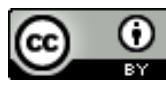

Esta obra está sob licença Creative Commons. 
que a verificação e a reunião dessas diferentes tradições e resistências foram possíveis sob o rótulo das Epistemologias e Teorias do Sul. A sociologia terceiro-mundista, as filosofias "latino-americana" e "africana", o grupo de Estudos Subalternos asiático, o pós-colonialismo e sua abordagem decolonial são alguns exemplos de esforços que trouxeram questionamentos em relação ao eurocentrismo, ao colonialismo acadêmico e ao imperialismo intelectual exercidos pelos centros de produção do conhecimento. As Teorias do Sul, portanto, rejeitam a ideia de que a produção teórica válida e aceitável no mundo é somente aquela realizada e autorizada pelas metrópoles; ao mesmo tempo, orientam-se pela democratização radical da construção coletiva e realmente global das Ciências Sociais (CONNELL, 2015; Gurminder K. BHAMBRA, 2014).

É deste contexto e perspectiva que parte nossa discussão sobre feminismos subalternos e a difícil relação entre teoria e prática. Basicamente, foi pelo mergulho no universo anteriormente exposto que chegamos ao feminismo do sul, e não pelo caminho contrário. Trata-se de uma observação epistemológica importante a ser feita, dado o imenso acúmulo teórico sobre feminismo e gênero em diferentes partes do mundo, inclusive no Brasil. Nosso alinhamento normativo explícito não poderá compensar as lacunas e omissões que eventualmente venham a aparecer ao longo deste texto quanto ao conhecimento da teoria feminista em geral. O mesmo pode ser aplicado ao imenso universo empírico ativista e militante, bem como às diferentes intersecções entre a realidade e a prática com o mundo abstrato dos conceitos e das ideias. Ainda assim, sabemos que realidade e teoria são mutuamente estabelecidas; a força dessa afirmação é ainda mais acentuada no caso dos movimentos sociais em geral e do movimento feminista em particular.

Nossa proposta, neste artigo, limita-se em analisar mais "teoricamente", por assim dizer, um encontro realizado nos anos 1980 e que, no entanto, tem tido profunda influência para a abertura da agenda no interior do próprio feminismo: trata-se do encontro entre o pós-colonialismo e o feminismo e vice-versa. Este encontro será explorado a partir das três dimensões teóricas propostas no título deste artigo: contribuições, tensões e limites para a cosmopolitização da agenda feminista. Necessariamente, uma cosmopolitização da agenda feminista envolve certa síntese entre o pós-colonialismo e o cosmopolitismo, o local e o global, o particular e o universal. Para isso, não há receitas ou caminhos seguros.

Por ora, convém notar que a expressão "feminismos subalternos" escolhida no título alude à subalternidade no interior do próprio feminismo, nos termos de Gayatri SPIVAK (2010). Aqui há uma dupla construção: ao mesmo tempo em que denunciam o silenciamento de várias expressões do feminismo (intencional?), os diversos feminismos subalternos agenciam um antagonismo irreconciliável diante de um feminismo "elitista", porque hegemônico: ocidental, branco, universalista, eurocêntrico e de Primeiro Mundo. Essa construção evidencia certo "essencialismo estratégico" - novamente, como propõe Spivak - no interior do próprio feminismo, e, portanto, nas relações intragênero. É importante notar que esse antagonismo é acentuado a partir da interiorização de marcadores como classe, etnia e nacionalidade - que andam sob a ótica interseccional ao lado das questões de gênero. Se assumirmos a razoabilidade dessas premissas, uma série de questões se abre em termos de identidade, diferença e (des)igualdade para o movimento e a teorização feminista em âmbito global.

O artigo está divido em duas partes principais. Na primeira seção, serão apresentadas algumas das principais questões colocadas pelo cruzamento das agendas pós-colonial e feminista, de maneira mais introdutória. Posteriormente, será explorada especificamente uma inflexão recente dos feminismos subalternos: o feminismo decolonial e do sul, via América Latina. O objetivo que permeia o texto é a tentativa de responder amplamente às seguintes perguntas: como a fictícia divisão geopolítica entre "Primeiro" e "Terceiro" mundos 
elaborada nos anos 1950 impactou na teorização feminista a partir dos anos 1980? De que maneira a exploração da desigualdade no interior da diferença "gênero" acentuou a fragmentação interna do movimento feminista? O que a eventual representação da mulher de Primeiro e Terceiro mundo implica para a luta pela igualdade do movimento feminista global? O antagonismo entre um movimento feminista do sul (subalterno) versus um movimento feminista do norte (hegemônico) é capaz de contemplar as injustiças sofridas pelas mulheres do sul do norte e a conivência com as mesmas das mulheres do norte do sul? Onde se encontram, neste caso, as outras?

\section{Pós-colonialismo e Feminismo: notas sobre um difícil encontro}

Uma das características peculiares do movimento feminista em relação aos outros movimentos sociais reside na sua capacidade de teorizar criticamente sobre si próprio (Céli Regina Jardim PINTO, 2010). Este entendimento nos permite compreender a articulação e a projeção de feminismos subalternos a partir dos anos 1980, sob as expressões Feminismo Terceiro-Mundista e Pós-Colonial. Porém, os encontros entre pós-colonialismo e feminismo não ficaram restritos a questões internas de ampliação e diversificação do movimento. As relações e intersecções entre feminismo e pós-colonialismo são muitas, podendo se dar de outras e diferentes maneiras.

Apesar de ambas correntes de pensamento possuírem uma trajetória autônoma e uma vocação transdisciplinar, as críticas feminista e pós-colonial compartilham de características e preocupações constitutivas dos movimentos históricos que as estruturam. Ania LOOMBA (2005, p. 39) assevera que tanto os movimentos feministas quanto os anticoloniais precisaram questionar as ideias dominantes de história e representação, uma vez que a cultura é vista como um campo de conflito entre opressores e oprimidos, no qual a linguagem pode ser uma ferramenta de dominação. Para ambos, a problematização do sujeito ocidental homem e branco nos discursos imperialistas europeus é um ponto de partida fundamental. Ainda, os/as intelectuais e ativistas feministas e anticoloniais possuem a perspectiva da transformação social (lbid.). Ambas epistemologias abalaram muitos pilares das ciências humanas e do seu próprio pensamento crítico. Os campos do conhecimento e da literatura são terrenos férteis para as análises feministas e pós-coloniais preocupadas com a invisibilidade, o silenciamento e a subalternidade dos sujeitos produzidos pelo patriarcado e pelo colonialismo. Não por acaso, é a mulher colonizada o sujeito subalterno "por excelência" que marcou o paradigmático encontro entre feminismo e pós-colonialismo, no provocativo e crítico ensaio de Gayatri Spivak, de 1988.

Anteriormente, o pós-colonialismo anticolonial de Franz FANON (2008) e a análise do discurso colonial inaugurada por Edward SAID (1978) em Orientalismo realizaram reflexões embrionárias sobre a mulher na condição colonial. Assim, a reflexão sobre a mulher no póscolonialismo foi introduzida desde uma perspectiva não feminista. Para o crítico literário palestino,

o próprio Orientalismo, além do mais, era uma província exclusivamente masculina; como tantas associações profissionais durante o período moderno, ele via a si e a seu tema com vendas sexistas sobre os olhos. Isso é evidente de maneira particular nos escritos de viajantes e romancistas: as mulheres são em geral criaturas de uma fantasia de poder masculina. Manifestam uma sexualidade ilimitada, são mais ou menos estúpidas e, acima de tudo, insaciáveis (SAID, 2007, p. 280-282)

Por sua vez, o psicanalista martinicano Franz Fanon dedicou dois capítulos sobre sexualidade em torno da relação entre "a mulher de cor e o branco" e "o homem de cor e a branca" em Peles negras, máscaras brancas, de 1952. Ainda que o autor tenha sido 
fundamental para vincular definitivamente racismo e colonialismo, introduzindo questões gênero e raça, o sujeito colonizado de Fanon foi, sobretudo, o homem negro. Para Loomba (2005, p. 137), a subjetividade feminina não foi adequadamente desenvolvida nas meditações fanonianas; tanto para Freud quanto para Fanon, a mulher ainda representava o mistério do "continente negro".

Na teoria feminista, a problematização sobre corpo, sexualidade e gênero é fundamental. No âmbito do pós-colonialismo não necessariamente feminista, esta problematização é, em geral, inserida nos contextos do encontro e da violência colonial. É como se o poder colonial fosse somado ao poder patriarcal; a violência sexual em particular aparece como fundamental para entendermos a violência colonial em geral. $\mathrm{O}$ corpo feminino pode ser pensado como o primeiro "território" a ser conquistado e ocupado pelo colonizador (homem, branco, cristão, europeu e heterossexual). Nas mais diversas situações de conflitualidades violentas, a vulnerabilidade do corpo feminino é acentuada: desde as conquistas coloniais, às guerras civis e interestatais, às ocupações e intervenções militares. Imperialismo, colonialismo e guerras foram, em geral, empreitadas masculinas e masculinizadas. Nesses contextos, a violação do corpo feminino por homens colonizadores, militarizados ou armados, do lado "amigo" ao "inimigo", repete-se histórica e violentamente. Na disciplina das Relações Internacionais, a perspectiva feminista, iniciada desde o final dos anos 1980, justifica-se neste tipo de ocorrência.

Quando o corpo e o sexo unem-se nas representações colonialistas, orientalistas e etnocêntricas de uma forma geral, o gênero feminino pode ser fantasiado como a cultura europeia (LOOMBA, 2005) e como os nomes continentais colonizados pela Europa: África, Ásia e América (Walter MIGNOLO, 2005). O imaginário erótico e sensual do colonialismo, envolvendo sedução e desejo na dimensão sexual da empreitada colonial pela posse e pela conquista, criou as representações da ameríndia despudorada, da oriental exótica, da africana fogosa. ${ }^{\prime}$ Contudo, nem todas as mulheres não europeias foram retratadas como desejáveis e passivas em algum lugar do mundo no imaginário desbravador colonial: as "Amazonas" são o exemplo de brutalidade, feminilidade desviante e sexualidade insaciável (LOOMBA, 2005, p. 131). Ainda, a relação entre nacionalismo e gênero foi bastante discutida por pesquisadoras feministas - a mulher como símbolo da nação, da descolonização (Deepika BAHRI, 2013, p. 661; Breny MENDOZA, 2009), e, poderíamos acrescentar, liberdade e paz. O "machismo", sabe-se, coexistiu com muitos movimentos nacionalistas (LOOMBA, 2005, p. 139).

Foi precisamente na década de 1980 que o feminismo encontrou o pós-colonialismo, sobretudo, através da crítica literária pela interpretação de textos e análises dos discursos coloniais e pós-coloniais (BAHRI, 2013, p. 660). Sob uma perspectiva de gênero, o estímulo à criação de objetos e ângulos de análise inovadores foi abrindo os caminhos para uma sintetização de ambos os movimentos teóricos: o feminismo pós-colonial. Apesar de a inserção do feminismo - tanto no pós-colonialismo como nos estudos culturais - ter adquirido um caráter de complementariedade e interseccionalidade, Sandra Regina Goulart ALMEIDA (2013, p. 690) afirma que esta não se deu de maneira tranquila, já que o feminismo teria a capacidade de desestabilizar edifícios teóricos bem construídos.

Em um artigo muito elucidativo de Deepika Bahri (2013, p. 660), traduzido e intitulado "Feminismo e/no Pós-colonialismo", a autora afirma que as contribuições feministas presentes

\footnotetext{
'Além disso, históricamente, la caracterización de las mujeres Europeas blancas como sexualmente pasivas y física y mentalmente frágiles las colocó en oposición a las mujeres colonizadas, no-blancas, incluidas las mujeres esclavas, quienes, en cambio, fueron caracterizadas a lo largo de una gama de perversión y agresión sexuales y, también, consideradas lo suficientemente fuertes como para acarrear cualquier tipo de trabajo (María LUGONES, 2008, p. 95-96).
} 
desde o início do pós-colonialismo canônico ajudaram-no a revisar, questionar e complementar suas próprias preocupações. Para ela, as questões de gênero são inseparáveis da crítica pós-colonial. Entretanto, existem também discórdias quando, por exemplo, o pós-colonialismo prescinde da análise de gênero ou o feminismo ignora questões relacionadas ao colonialismo e à divisão internacional do trabalho.

Neste segundo caso, o pós-colonialismo foi fundamental para estimular uma crítica interna no interior do próprio movimento feminista. Menos analítica e mais política, acadêmica e intelectual, é esta segunda inflexão do feminismo pós-colonial que gostaríamos de explorar.

\section{Feminismo terceiro-mundista}

Em 1980, a década de difusão dos estudos pós-coloniais e da própria divulgação do termo "pós-colonialismo", o feminismo encontrava-se na segunda fase de sua segunda onda, ou seja, mergulhando na política de identidades, segundo a periodização trabalhada por Nancy FRASER (2007). A filósofa feminista estadunidense, de grande importância teórica, é franca quanto à "autocongratulação" dessa mesma política de identidades no interior do movimento feminista:

É claro que eu apoio os esforços para ampliar e diversificar o feminismo, mas não acho que essa seja uma narrativa satisfatória. No meu ponto de vista, ela é muito interna ao feminismo (p. 292).

Nesta passagem, Fraser faz uma crítica a uma suposta e progressiva inclusão de mulheres subalternizadas no interior do movimento feminista dos Estados Unidos; um movimento branco, heterossexual e de classe média, que teria, aos poucos, incorporado as preocupações das mulheres negras, lésbicas, pobres e trabalhadoras. A autora trata com certa indiferença e pouca importância tais tentativas de democratização interna quanto à diversidade e à representatividade das mulheres em movimento. Para Mendoza (2014, p. 322), o problema da análise de Fraser é sua paroquialidade: seja na sua incapacidade de pensar as estruturas econômicas transnacionais, seja pelo bias euro-americano do esquema de redistribuição econômica e reconhecimento cultural.

No importante livro The Empire Writes Back..., originalmente publicado em 1989, seus autores demonstram a importância da literatura e da crítica literária para o nascimento do pós-colonialismo e seu desenvolvimento paralelo com novas inclinações da teoria feminista. Bill ASHCROFT, Gareth GRIFFITHS e Hellen TIFFIN (2002, p. 173) argumentam que a interseccionalidade entre gênero, raça e classe tornou-se fundamental para a mesma devido às críticas recebidas de algumas escritoras e do redimensionamento para as questões da "diferença" e do "outro". Em outras palavras, a década de 1980 foi muito propícia para o encontro do feminismo com o pós-colonialismo e o pós-colonialismo com o feminismo. E assim, paradoxalmente, o feminismo pós-colonial - como o próprio póscolonialismo - não nasceu dos contextos pelos quais pretendeu intervir (o Terceiro Mundo, hoje Sul Global); surgiu da diáspora biográfica e acadêmica onde pôde se autojustificar.

Enquanto isso, o feminismo brasileiro - terceiro-mundista? -, à época, atravessava o contexto da redemocratização que inaugurou sua terceira fase no país ${ }^{2}$ e construía o espaço para a luta de vários direitos civis e sociais das mulheres: combate à violência e ao racismo, direitos à saúde, trabalho, terra e sexualidade (PINTO, 2010). Estas observações

\footnotetext{
2 Matos (2010) defende que, atualmente, o feminismo brasileiro estaria vivenciando uma quarta onda, marcada principalmente pela "democratização de gênero no âmbito das instituições e da (re)formulação de políticas públicas" (p. 83).
} 
são importantes, pois o feminismo pós-colonial não nasceu de um diálogo entre mulheres acadêmicas do Primeiro e do Terceiro Mundo.

Nesse sentido, a construção de um profundo antagonismo no interior do movimento feminista foi ocorrendo paralelamente à sua própria internacionalização, no decorrer dos anos 1970, expressando-se com mais evidência na década de 1980. Com efeito, o processo de transnacionalização do feminismo observado nas três últimas décadas e seu estímulo por vários fóruns internacionais - oficiais e informais - e pela estrutura de oportunidades oferecidas pela globalização, projetou desafios em relação à articulação de uma desejada global sisterhood (MENDOZA, 2002). O desafio pós-colonial foi posto na prática no interior do movimento.

O feminismo ocidental - dos quais o estadunidense faz parte - passou a ser acusado por seu universalismo, etnocentrismo, anglo-eurocentrismo, branqueamento e pela negligência de questões coloniais e raciais que atravessam etnias, nacionalidades e geografias. Passou, também, a ser retratado como um feminismo do Norte e de Primeiro Mundo, muito pouco sensível às questões das mulheres não ocidentais, do Sul e do Terceiro Mundo. Nesta denúncia, simplificações, generalizações e não diferenciações em termos de identidade, representação e interesse também acabaram por surgir. Estabeleceu-se uma bipolaridade no interior do feminismo, com dois polos antagônicos e irreconciliáveis em torno de uma diferença aparentemente "geopolítica"; o feminismo terceiro-mundista, contudo, ao denunciar o colonialismo intelectual das acadêmicas feministas ocidentais, construiu uma cadeia de equivalência discursiva "inversa". E, assim como o feminismo ocidental passou a ser julgado por essencializar, inferiorizar e vitimizar as mulheres do "Terceiro Mundo", o feminismo terceiro-mundista respondeu utilizando a mesma operação ao essencializar, superiorizar e responsabilizar as mulheres feministas do Primeiro Mundo. Qual a estratégia para a marcação de um essencialismo binário, no entanto, dentro do próprio movimento feminista?

O quadro 1 "representa representações", conforme nossa literatura.

Provisoriamente, gostaríamos de sugerir que a ideia de feminismos subalternos pode agregar diferentes movimentos de mulheres feministas, acadêmicas ou não: feminismo pós-colonial, feminismo terceiro-mundista, feminismo negro, feminismo indígena, feminismo comunitário, feminismo mestiço, feminismo latino-americano, feminismo africano, feminismo islâmico, feminismo do Sul, feminismo decolonial, feminismo fronteiriço, feminismo transcultural etc. Em geral, esse amplo espectro de caracterizações está relacionado com marcações geopolíticas, étnico-raciais e culturais. Tal como trabalhado no impactante ensaio de Chandra Talpade MOHANTY (2008 [1984]), o feminismo terceiro-mundista ou póscolonial questionou o caráter "colonial" do discurso feminista ocidental ao criar representações estereotipadas da "mulher do terceiro mundo" muito distantes das ideias de agência, liberação, emancipação e autonomia.

Ampla e internacionalmente muito debatido, já nas primeiras linhas de Under western eyes..., Mohanty (2008) é bastante atenta à cilada da inversão ao propor uma análise do discurso de textos feministas ocidentais que retratam a "mulher do terceiro mundo como um sujeito monolítico e singular" (p. 112). Assim,

el discurso y la práctica política del feminismo occidental no son ni singulares ni homogéneos en sus objetivos, intereses o análisis. Sin embargo, es posible rastrear una coherencia de efectos que resultan del supuesto implícito de "Occidente" - con todas sus complejidades y contradicciones - como referente primario en teoría y praxis. Mi referencia al "feminismo de Occidente" no pretende de ninguna forma sugerir que se trata de un conjunto monolítico. Más bien busco hacer notar los efectos similares de varias estrategias textuales utilizadas por escritoras que codifican al Otro como no 
Quadro 1: Representações antagônicas do movimento feminista e de mulheres

\begin{tabular}{|c|c|c|}
\hline $\begin{array}{l}\text { Marcadores } \\
\text { (Movimento) }\end{array}$ & $\begin{array}{l}\text { Feminismo } \\
\text { "Hegemônico" }\end{array}$ & $\begin{array}{l}\text { Feminismos } \\
\text { "Subalternos" }\end{array}$ \\
\hline Geopolítica & $\begin{array}{c}\text { Ocidental } \\
\text { Primeiro Mundo } \\
\text { Norte Global } \\
\text { América do Norte/Europa }\end{array}$ & $\begin{array}{c}\text { Não ocidental } \\
\text { Terceiro Mundo } \\
\text { Sul Global } \\
\text { Ásia } \\
\text { África } \\
\text { América Latina e Caribe } \\
\text { Oceania }\end{array}$ \\
\hline $\begin{array}{c}\text { Referências } \\
\text { espaço-tempo } \\
\text { políticas-culturais }\end{array}$ & $\begin{array}{l}\text { Moderno } \\
\text { Secular } \\
\text { Estado-nação } \\
\text { Urbano }\end{array}$ & $\begin{array}{c}\text { Não moderno } \\
\text { Religioso (ex.: Islâmico) } \\
\text { Comunitário, comunal } \\
\text { Rural }\end{array}$ \\
\hline Dimensão & Global, Universal & Local, Particular \\
\hline $\begin{array}{l}\text { Marcadores } \\
\text { (Mulheres) }\end{array}$ & $\begin{array}{l}\text { Representações } \\
\text { "Hegemônicas" }\end{array}$ & $\begin{array}{l}\text { Representações } \\
\text { "Subalternas" }\end{array}$ \\
\hline $\begin{array}{l}\text { Raça } \\
\text { Etnia } \\
\text { Cor }\end{array}$ & Brancas & $\begin{array}{l}\text { Negras } \\
\text { Mestiças } \\
\text { Indígenas } \\
\text { De "cor" } \\
\text { De "cor de café" } \\
\text { "Chicanas" }\end{array}$ \\
\hline $\begin{array}{l}\text { Classe } \\
\text { Trabalho } \\
\text { Escolaridade } \\
\text { Autonomia }\end{array}$ & $\begin{array}{l}\text { Classe Média } \\
\text { Acadêmicas } \\
\text { Escolarizadas } \\
\text { Autônomas/liberadas }\end{array}$ & $\begin{array}{c}\text { Pobres } \\
\text { Trabalhadoras } \\
\text { Pouco escolarizadas } \\
\text { Dominadas/vítimas }\end{array}$ \\
\hline
\end{tabular}

occidental y, por tanto, (implícitamente) a sí mismas como "occidentales". Es en este sentido que utilizo el término feminismo occidental.

Mohanty chamou atenção para a colonização discursiva acadêmica e de produção intelectual de mulheres do Primeiro Mundo sobre mulheres de Terceiro Mundo. Além de essas próprias categorias serem coloniais, a transformação das "mulheres de Terceiro Mundo" em objeto de pesquisa, interesse e intervenção sugere certo imperialismo do feminismo ocidental (Leela GANDHI, 1998). Acrescentou ainda que tais estratégias analíticas também podem ser observadas nas

académicas de clase media urbana en África o Asia que producen estudios académicos acerca de sus hermanas rurales o de clase trabajadora en los que asumen sus culturas de clase media como la norma y codifican las historias y culturas de la clase trabajadora como el Otro" (p. 113).

Para Mohanty, a colonização sempre implica formas de dominação e supressão da heterogeneidade dos sujeitos em questão - uma vaga definição, conforme Leela Gandhi (1998, p. 85). 
Assumindo que as categorias de "Primeiro" e de "Terceiro" mundos são problemáticas, a autora expõe seu desenho e recorte de pesquisa que permite a aferição da representação de uma "mulher média de Terceiro Mundo", a qual geralmente é retratada como pobre, ignorante, limitada pela tradição e pela família, em contraparte às mulheres conscientes, emancipadas, modernas, controladoras de seu corpo e sexualidade. Essas deduções só são possíveis mediante a aceitação de certas premissas etnocêntricas e homogeneizadoras. Sua metodologia permitiu concluir que textos analisados com diferentes graus de sensibilidade e complexidade apontam para representações similares das mulheres do Terceiro Mundo, como vítimas da violência masculina, do processo colonial, do sistema familiar árabe, do desenvolvimento e do código islâmico. Mohanty procura chamar atenção para certo "paternalismo" das feministas ocidentais de diferentes matizes - liberais, radicais, marxistas - em relação às suas "outras" mais abaixo, supostamente em uma escala de opressão masculina.

Por ocasião da coletânea Descolonizando el feminismo..., editada por Liliana Suárez NAVAZ e Rosalva Aída Hernández CASTILLO e publicada em 2008, uma série de artigos críticos ao feminismo hegemônico foi traduzida para o espanhol, incluso o texto original de Mohanty, de 1984, e uma revisita pela própria autora do mesmo em De vuelta a Bajo los ojos de Ocidente... (MOHANTY, 2008a). Assumindo sua posição como educadora, professora e acadêmica nos Estados Unidos - não mais sob, e, sim, adentro -, a autora procura reforçar as principais ideias e objetivos do texto, reconhecendo algumas limitações, ambiguidades e críticas que o mesmo recebeu devido à sua enorme e inesperada repercussão na academia internacional. É preciso reafirmar que a autora reconhece que as categorias Primeiro e Terceiro Mundo são muito complicadas por sua simplificação e homogeneização. A "diferença" adicional "Terceiro Mundo" para pensar a vida das mulheres acabou por acompanhar o que o termo implica e significa em termos de "desenvolvimento", isto é, mulheres "menos desenvolvidas". Ambas as categorias/identidades, a autora lembra, habilitam e sustentam uma a outra.

Atentando para interpretações errôneas e equivocadas do texto anterior, Mohanty reforça alguns dos seus objetivos na ocasião, dentre eles demonstrar a metodologia eurocêntrica, universalista e falaciosa utilizada pelas acadêmicas do Primeiro Mundo para estudar as mulheres do Terceiro Mundo (colonização discursiva), convertendo-as em objetos e não em sujeitos. Notou, também, a importância de estarmos atentas para as complexidades históricas, formas de resistência, subjetividade, agenciamento e luta diante da opressão às mulheres que também assumem diferentes formatos. Ao chamar a atenção para a importância do contexto, Mohanty não pretendeu afastar o feminismo branco; pelo contrário, de acordo com a leitura de Sylvia Walby (apud MOHANTY, 2008a). Segundo ela, a estratégia de Mohanty foi convencer as feministas ocidentais apostando na razoabilidade de seus argumentos. Ao defender que sua crítica deve se dar dentro de um marco de solidariedade e valores compartilhados, Mohanty (2008a) explica-se:

Mi insistencia en la especificidad de la diferencia tiene su base en una visión igualmente atenta a las diferencias de poder dentro de las varias comunidades de mujeres y entre ellas. No argumenté en contra de todas las formas de generalización, ni tampoco privilegié lo local sobre lo sistémico, la diferencia sobre lo común, ni lo discursivo sobre lo material (p. 409).

Prossegue com um tom de lamento e surpresa (2008a):

No escribí "Bajo los ojos de Occidente" como testamento a la imposibilidad de una práctica académica transcultural igualitaria y no-colonizadora, ni definí los feminismos "Occidental" y "tercermundista" en términos tan antagónicos que cerraran la posibilidad 
de solidaridad entre las feministas de Occidente y las del Tercer Mundo. Sin embargo, es así como el ensayo ha sido interpretado y utilizado frecuentemente. Me he preguntado por qué el ensayo desarrolló una oposición tan aguda en esta forma.

Como consequência, desconfiança e ressentimento aparecem com frequência entre as diferentes tendências no interior do movimento feminista. Assim, diferentes movimentos de mulheres pós-coloniais veem com bastante ceticismo certas agendas associadas ao feminismo ocidental (ALMEIDA, 2013, p. 692). De outra parte, "no âmbito mais amplo do feminismo predominante, as perspectivas pós-coloniais que enfocam a raça e a etnicidade podem ser percebidas como forças que fragmentam a aliança feminista mundial" (BAHRI, 2013, p. 663) e dificultam o caminho rumo a uma irmandade global (global sisterhood). Ainda, pensando em termos analíticos, diferentes estudos pós-coloniais demonstraram a possibilidade de conivência e cumplicidade das mulheres com a empresa colonial (lbid.).

Há muito espaço, contudo, para a colaboração entre pós-colonialismo e feminismo, como diversas autoras apostam. A própria crítica pós-colonial exercida no interior do feminismo auxilia-o a pensar e a construir estratégias de luta mais representativas e inclusivas no século $X X I$ - isso, no entanto, não deve nos levar a crer que no interior do próprio feminismo póscolonial não haja profundas tensões e problemas. De acordo com Bahri (2013, p. 663), o feminismo pós-colonial é um campo discursivo dinâmico capaz de questionar as premissas do pós-colonialismo e do feminismo, sendo caracterizado pelo debate, diálogo e diversidade. Analiticamente, a observação sobre "o conluio entre o patriarcado e o colonialismo" (lbid.) e "a ofensiva combinada contra o mito agressivo tanto da masculinidade nacionalista como imperial" (GANDHI, 1998, p. 98) são caminhos interessantes para pensar o colonialismo e a guerra como masculinidades em disputa. Loomba (2005, p. 140) afirma que o feminismo póscolonial chama a atenção, por exemplo, para a omissão das enormes diferenças culturais, geográficas e raciais contida na ideia de "mulher negra". Para Ascroft et al. (2002, p. 206), os links entre feminismo e pós-colonialismo ocupam grande parte das preocupações atuais dos estudos pós-coloniais.

À semelhança do pós-colonialismo, o feminismo pós-colonial é enunciado das grandes universidades do Norte, sobretudo nos Estados Unidos e na Inglaterra. Ou seja, se existe um feminismo terceiro-mundista, mesmo que somente em nível acadêmico e universitário, ele não é enunciado das universidades do Terceiro Mundo ou Sul global. Isso remete aos problemas introduzidos neste artigo sobre as dinâmicas da geopolítica do conhecimento. É preciso perguntarmos: se Mohanty permanecesse na Índia, seus textos teriam o mesmo impacto? Ou melhor, nossa autora teria tido acessos que the permitiram desenvolver seus pensamentos e argumentos? Talvez não. Esse permanece sendo um dos grandes paradoxos do pós-colonialismo, isto é, o fato de que grande parte suas teorias pelo menos de sua popularização e de sua divulgação - não provém de contextos póscoloniais ou terceiro-mundistas (ainda que seus autores/as se identifiquem na diáspora pós-colonial de suas trajetórias de vida).

Em geral, sabe-se que as conexões teóricas, acadêmicas e ativistas Sul-Sul são facilitadas, estabelecidas e muitas vezes mediadas pelo Norte. No caso da América Latina, a inserção do debate pós-colonial é recente, assim como o é seu próprio enquadramento no âmbito do pós-colonialismo. Ainda que utilize, recupere e reivindique diferentes contribuições latino-americanas para a construção de um "pós-colonialismo não colonizado" desde o continente, grande parte do estímulo e do incentivo ao seu debate foi proporcionado e calibrado via Estados Unidos. Além dos problemáticos estudos de área onde figuram os Latin American Studies e do grande número de intelectuais que lá fixaram sua residência e trabalho, o país conta com um vigoroso debate acadêmico pós-colonial observado em diferentes iniciativas - departamentos, programas, revistas, grupos, publicações, sites etc. A versão pós- 
colonial da América Latina (decolonial) possui uma série de especificidades que influenciarão diretamente o feminismo decolonial. Ele reedita o feminismo terceiro-mundista, autodenominando-se também como feminismo do sul e feminismo fronteiriço (uma alusão ao conceito de pensamento de fronteira ou fronteiriço de Walter Mignolo). Essa atualização, contudo, restringe-se às universidades dos Estados Unidos e países da América Latina em relação aos seus principais lugares de enunciação, procurando resgatar diferentes feminismos da região (chicano, negro, latino-americano). O feminismo decolonial - em certos sentidos possui uma trajetória parecida e abertamente inspirada no grupo Modernidade/Colonialidade. E, como Walter Mignolo, María Lugones é uma argentina que construiu sua carreira acadêmica e ativismo feminista nos Estados Unidos.

\section{Modernidade e Colonialidade de Gênero: o feminismo descolonial}

A agenda da descolonização do feminismo data e acompanha um determinado diagnóstico colonial do feminismo ocidental, não sendo propriamente uma novidade. Esta visão tem sido construída desde os anos 1980, sendo bem representada pelas primeiras palavras - constantemente citadas - do ensaio de Mohanty (2008):

Cualquier discusión sobre la construcción intelectual y política de las "feminismos del tercer mundo" debe tratar dos proyectos simultáneos: la critica interna de los feminismos hegemónicos de "Occidente", y la formulación de intereses y estrategias feministas basados en la autonomía, geografía, historia y cultura (p. 112).

De fato, os anos oitenta foram um marco para a ascensão de diferentes processos, problemas e agendas do mundo contemporâneo que (des)conectam o norte e o sul: globalização, neoliberalismo, multiculturalismo, pós-modernidade, pós-colonialismo. Claudia de LIMA COSTA (2014) construiu uma interessante explicação para a emergência da crítica pós-colonial:

[Ela] surge, então, como uma tentativa teórica e metodológica de preencher o vácuo analítico causado pela proliferação de novas temporalidades disjuntivas e instabilidades do capitalismo contemporâneo, bem como pela complexificação das relações e assimetrias de poder (p. 278).

Apesar de possuir uma série de críticas pertinentes e importantes (Anne McCLINTOCK, 1992; Arif DIRLIK, 1994; Aijaz AHMAD, 2002), o pós-colonialismo é fundamental para entendermos as outras dimensões do colonialismo que não só as econômicas, não significando que as mesmas possam ser deslocadas de uma base material que o motivou. Como sustentado por alguns autores (LOOMBA, 2005; Miguel MELLINO, 2008), o encontro do pós-colonialismo com o marxismo para a explicação dos processos coloniais e imperiais deveria ser muito mais produtivo e complementar. Por exemplo, aplicando certas premissas da economia política internacional, observa-se um vínculo bastante estreito com as questões colocadas pelos feminismos subalternos. "A mulher do terceiro mundo" talvez seja a melhor síntese do cruzamento entre marxismo, pós-colonialismo e feminismo.

A proposta de um feminismo decolonial, apesar de envolver certa descolonização do feminismo, não pode ser considerada seu sinônimo. Por parte de suas autoras entusiastas, existe uma clara tentativa de marcar sua distinção dos feminismos outros. Essa distinção dá-se por filiação teórica, influência e geografia. À semelhança de certas estratégias discursivas, retóricas e teóricas decoloniais, o feminismo decolonial faz questão de colocar as Américas e a América Latina, em particular, como mapa de sua referência. Vincula-se epistemologicamente com o grupo Modernidade/Colonialidade. 
Tal programa de investigação, assim denominado pelo antropólogo Arturo ESCOBAR (2003), pretendeu inserir a América Latina e propor o giro decolonial no debate global sobre pós-colonialismo. Em outro lugar, trabalhamos com a formação, influências teóricas e propostas desse grupo (Luciana BALLESTRIN, 2013). Passados dois anos de sua publicação, é possível verificar um significativo crescimento da abordagem decolonial latino-americana no Brasil e em outras partes do mundo - atualmente, as leituras brasileiras do movimento são mais contemplatórias do que analíticas e críticas. A proposta ou o giro decolonial tem ainda ganhado legitimidade nas discussões sobre teorias, sociologias e epistemologias do sul (CONNELL, 2015). Ao mesmo tempo, observa-se uma desmistificação do programa de investigação Modernidade/Colonialidade (M/C) como um grupo relativamente coeso e agregado, que periodicamente reúne-se e teoriza coletivamente - enfim, como um coletivo que se constitui como tal. Em diferentes entrevistas com seus supostos integrantes, é possível perceber tons de desagregação e questionamento sobre sua própria existência. Uma das razões para isso talvez seja a larga trajetória acadêmica que muitos dos seus membros possuem na construção das humanidades na América Latina.

A ausência sobre as discussões de gênero no interior do $M / C$ foi documentada no artigo de Escobar (2003), juntamente com a ausência sobre as questões sobre natureza, ambiente e economias alternativas. É muito provável que essas ausências tenham levado Mignolo (2010) a ramificar diferentes tipos de controle - da economia, autoridade, natureza/ recursos naturais, gênero/sexualidade e subjetividade/conhecimento - como base do conceito pioneiro e original de Aníbal QUIJANO de "Colonialidade do Poder". O feminismo descolonial trata-se de uma intervenção teórica sobre a ideia de gênero e sexo no esquema de Quijano, amparando-se e animando-se empiricamente nos diferentes feminismos americanos - latino, negro, chicano, "de cor", indígena e comunitário. Nos últimos anos, é associado e referido também como "feminismos do sul".

\section{Feminismo descolonial}

A partir da aceitação das críticas pioneiras da teóloga e feminista finlandesa Elina Vuola ao trabalho de Enrique Dussel, Escobar (2003) assume o quão masculino é o M/C em termos de constituição, bem como a omissão e a exclusão em relação às questões de gênero. O antropólogo admite que "el sujeto de la diferencia colonial no es un sujeto indiferenciado género-neutral" (lbid., p. 73), reconhece a necessidade de um engajamento feminista no projeto decolonial e identifica seus pontos em comum. Para entender a colonialidade, a construção da noção de raça e as formações eurocêntricas-patriarcais são importantes; daí que as contribuições das feministas latino-americanas aparecem como fundamentais (lbid., p. 75). Inclusive, o feminismo chicano dos trabalhos de Glória Anzaldúa influenciou alguns conceitos de Walter Mignolo. Escobar (2003) relembra o debate sobre o qual falamos na seção anterior:

Es verdad que después de las críticas realizadas por las mujeres de color y del Tercer Mundo en los ochenta, los supuestos feminismos universales han sido más conscientes de las dimensiones raciales y culturales de las dinámicas de género; sin embargo, variedades del eurocentrismo continúan siendo predominantes en un número de posiciones feministas. El lenguaje de la "diferencia colonial" introduce nuevamente este punto complicando, por ejemplo, los supuestos sobre el género que son aún formados por nociones euro céntricas de liberación e igualdad; eso ayudará a explicar las coaliciones subalternas que no necesariamente abrazan las demandas de género o siguen una lógica de solidaridad entre las mujeres - sobre las solidaridades de etnicidad y clase (p. 76-77). 
As contribuições da abordagem decolonial em relação ao gênero foram sendo estruturadas a partir de algumas considerações mais contemporâneas de seus principais autores, um deles o sociólogo peruano Aníbal Quijano (1928- ). O autor, que possui uma larga e importante trajetória na sociologia latino-americana desde os anos 1960, reconhece a incapacidade do materialismo histórico em incorporar outros eixos de poder hierarquizantes e exploradores, tais como raça, gênero e idade. Dada sua formação marxista, Quijano (2000) interessa-se em ampliar seus horizontes de preocupação para o desenvolvimento do seu conceito de Colonialidade do Poder:

A colonialidade é um dos elementos constitutivos e específicos do padrão mundial de poder capitalista. Se funda na imposição de uma classificação racial/étnica da população do mundo como pedra angular do dito padrão de poder e opera em cada um dos planos, âmbitos e dimensões materiais e subjetivas da existência social cotidiana e da escala social. Origina-se e mundializa-se a partir da América (p. 342).

Raça, gênero e trabalho teriam sido para o autor as três linhas principais de classificação que constituíram a formação do capitalismo mundial colonial/moderno no século XVI (QUIJANO, 2000, p. 342). É em torno dessas três instâncias que as relações de exploração/dominação/conflito estão ordenadas. A identificação dos povos de acordo com suas faltas ou excessos é uma marca fundamental da diferença colonial produzida e reproduzida pela colonialidade do poder - em particular, o poder colonial (MIGNOLO, 2003, p. 39) -, do saber e do ser (Nelson MALDONADO-TORRES, 2007, p. 147). O conceito de colonialidade do poder sugere as invenções da raça e do racismo como princípios organizadores e estruturantes das múltiplas hierarquias do sistema-mundo, segundo Ramón GROSFOGUEL (2008, p. 123). Se a raça é uma categoria mental da modernidade, tem-se que seu sentido moderno não tem história conhecida antes da América.

Raciocínio semelhante será aplicado por Quijano (2000) à noção de gênero:

En No-Europa habían sido impuestas identidades "raciales" no-europeas o "no-blancas". Pero ellas, como la edad o el género entre los "europeos", corresponden a diferencias "naturales" de poder entre "europeos" y "no-europeos". En Europa están en formación o ya están formadas las instituciones "modernas" de autoridad: los "estados-nación modernos" y sus respectivas "identidades" (p. 366).

Para desenvolver "a colonialidade das relações de gênero", Quijano (2000) afirma, em contraposição à ideia de raça, que a "produção social da categoria gênero a partir do sexo é sem dúvida a mais antiga na história social" (p. 373). Por outro lado, as relações de gênero teriam sido ordenadas pela lógica da colonialidade do poder. ${ }^{3}$ Eis uma das passagens mais problemáticas desta elaboração de Quijano (2000):

\footnotetext{
${ }^{3}$ Porque, segundo o autor: (1) En todo el mundo colonial, las normas y los patrones formal-ideales de comportamiento sexual de los géneros y en consecuencia los patrones de organización familiar de los "europeos" fueron directamente fundados en la clasificación "racial": la libertad sexual de los varones y la fidelidad de las mujeres fue, en todo el mundo eurocentrado, la contrapartida del "libre"- esto es, no pagado como en la prostitución, más antigua en la historia - acceso sexual de los varones "blancos" a las mujeres "negras" e "indias," en América, "negras" en el Africa, y de los otros "colores" en el resto del mundo sometido. (2) En Europa, en cambio, fue la prostitución de las mujeres la contrapartida del patrón de familia burguesa. (3) La unidad e integración familiar, impuestas como ejes del patrón de familia burguesa del mundo eurocentrado, fue la contrapartida de la continuada desintegración de las unidades de parentesco padreshijos en las "razas" no-"blancas", apropiables y distribuibles no sólo como mercancías, sino directamente como "animales". En particular, entre los esclavos "negros", ya que sobre ellos esa forma de dominación fue más explícita, inmediata y prolongada. (4) La característica hipocresía subyacente a las normas y valores formal-ideales de la familia burguesa, no es, desde entonces, ajena a la colonialidad del poder (lbid., p. 377 378).
} 
La "naturalización" mitológica de las categorías básicas de la explotación/dominación es un instrumento de poder excepcionalmente poderoso. El ejemplo más conocido es la producción del "género" como si fuera idéntico a sexo. Muchas gentes piensan que ocurre lo mismo con "raza" respecto, sobre todo, de "color". Pero esta es una radical confusión. Después de todo, el sexo es realmente un atributo biológico (implica procesos biológicos) y algo tiene que ver con "genero". Pero "color" es, literalmente, un invento euro céntrico en tanto que referencia "natural" o biológica de "raza", ya que nada tiene que hacer con la biologia (p. 379).

A frase sublinhada na citação anterior vai na contracorrente das elaborações feministas contemporâneas sobre identidade, "gênero" e "sexo", particularmente nas teorizações queer (BUTLER, 2015). A desconstrução e o questionamento da própria noção histórica de "sexo", vinculada pela ciência moderna ocidental à anatomia e à biologia, possuem um papel importante aqui. No entanto, fica evidente o esforço que Quijano realizou em se despojar de seus registros e constructos marxistas e dependentistas para incorporar gênero e raça, mesmo que em um quadro limitado e questionável de interseccionalidade.

A negação da humanidade das pessoas colonizadas e escravizadas desde o encontro colonial/moderno teria sido possível através da construção dos pensamentos binários que passaram a regular a modernidade ocidental - natureza/cultura; barbárie/ civilização; corpo/razão; negro/branco; homem/mulher. Este raciocínio - trabalhado pela antropologia estruturalista e base da crítica pós-estrutural e desconstrutivista - é o que permite a grande parte dos autores decoloniais explicar a brutalidade e a violência com que foram tratados indígenas, mulheres e escravizados desde o encontro colonial/moderno. Se, "às Américas chegou o homem heterossexual/branco/patriarcal/cristão/militar/capitalista europeu” (GROSFOGUEL, 2008, p. 113), tem-se que essas hierarquias teriam sido transpostas pelos colonizadores. Mignolo e Grosfoguel procuram inserir a categoria "gênero" em suas análises partindo de simplificações como essa, sem maiores aprofundamentos.

É reincidente no pensamento decolonial a concepção da modernidade/ colonialidade como fundação e origem das desigualdades contemporâneas. Comprometendo-se com a lacuna sobre gênero nas teorizações do $\mathrm{M} / \mathrm{C}$, a feminista nascida na Argentina e residente nos Estados Unidos María Lugones pretende intervir nesse debate propondo a noção de "sistema-mundo/colonial de gênero" e "feminismo descolonial" (LUGONES, 2008; 2014). Sua proposta de gênero como categoria colonial/moderna convida a historicizar o patriarcado, ao mesmo tempo em que contesta a tese de Quijano: "a imposição de um sistema de gênero binário foi tão constitutiva da colonialidade do poder quanto esta última foi constitutiva de um moderno sistema de gênero" (LIMA COSTA, 2014, p. 281). Gênero e raça teriam sido constructos coloniais com o objetivo de racializar e engendrar as sociedades colonizadas (lbid., p. 282). A separação categorial, marca da modernidade colonial, sobretudo entre humanos e não humanos, esconde em si mesma sua violência (LUGONES, 2008; 2014). Assim, "como el capitalismo eurocentrado global se constituyó a través de la colonización, esto introdujo diferencias de género donde, anteriormente, no existía ninguna" (LUGONES, 2008, p. 86). As características específicas e aparentes da organização de gênero, a partir da constituição do "sistema-mundo moderno/colonial de gênero", compreendem "o dimorfismo sexual, a organização patriarcal e heterossexual das relações patriarcais" (lbid., 78).

Esta afirmação parte da generalização dos trabalhos da nigeriana Oyéronké Oyewùmi sobre os Yorubas e de Paula Allen sobre diferentes tribos nativas norte-americanas ginecráticas antes do contato com os colonizadores. Lugones compra sem questionamentos a tese de Oyewùmi de que "el género no era un principio organizador en la sociedad Yoruba antes de la colonización Occidental" (apud LUGONES, 2008, p. 87). Convence-se 
prontamente de que "Allen de talla las transformaciones de las ginecracias Cherokee e Iroqués y del rol de los hombres indios en el pasaje hacia el patriarcado" (lbid., p. 90). Esses estudos de caso creditados sem a devida referência metodológica são generalizados por Lugones para todo o mundo colonial. ${ }^{4}$ Ambas as autoras, ressalta, preocuparam-se em demonstrar a cumplicidade entre colonizadores e colonizados na construção de novas hierarquias baseadas no gênero. Sua conclusão indutiva carece de evidências históricas e de representatividade empírica - no caso, indispensável para uma generalização do não histórico e do não universal. Assim, a nosso ver, o problema de Lugones é metodológico: a partir de um punhado de casos secundários, estabelece uma proposição de caráter universal.

Em uma resenha crítica sobre o trabalho de Oyewùmi, Bibi BAKARE-YUSUF (2003) afirma que alguns trabalhos feministas recentes baseados em culturas não europeias procuraram demonstrar que outras categorias para organizar a vida social aparecem como mais importantes do que as hierarquias de gênero (como idade e sexualidade). Isso pode sugerir uma validade temporal e histórica do patriarcado, ainda que a maior tendência seja a de reconhecer que a diferença de gênero é central pelo mundo afora. A autora pergunta-se: podem gênero e patriarcado serem categorias aplicadas fora do contexto europeu e americano? Pode-se assumir que todas as sociedades são organizadas em torno da diferença sexual/biológica (lbid., p. 121)? O argumento de Oyewùmi que sustenta não ser o gênero uma categoria relevante para muitas sociedades africanas, em particular os Yorubas, é criticado por Bakare-Yusuf pela sua incapacidade de investigar seriamente os corpos sexuados e suas implicações para diferentes aspectos da vida social. Já Rita SEGATO (apud LIMA COSTA, 2014, p. 282) encontrou evidências de referências ao gênero no seu estudo sobre os Yorubas e manifestações patriarcais, ainda que diferentes do Ocidente.

Desde a década de 1960, Lugones vê-se comprometida com os "feminismos de cor" - as mulheres de ascendência asiática, indígena norte-americana e africana, latinoamericana residentes nos EUA (BIDASECA, 2014a) -, possuindo um engajamento militante e acadêmico nos feminismos latino-americanos - especialmente, Argentina e Bolívia (BIDASECA, 2014a). No artigo "Rumo a um feminismo descolonial", Lugones (2014) afirma seu atual comprometimento com o projeto descolonial e seu deslocamento dos feminismos de cor; introduz questionamentos e novas proposições:

Descolonizar o gênero é necessariamente uma práxis. É decretar uma crítica da opressão de gênero racializada, colonial e capitalista heterossexualizada visando a uma transformação vivida do social. [...]. Deve incluir "aprender" sobre povos. [...]. Começo aqui a fornecer uma forma de compreender a opressão de mulheres subalternizadas através de processos combinados de racialização, colonização, exploração capitalista e heterossexualismo. Minha intenção é enfocar na subjetividade/intersubjetividade para revelar que, desagregando opressões, desagregam-se as fontes subjetivas intersubjetivas de agenciamento das mulheres colonizadas. Chamo a análise da opressão de gênero racializada capitalista de "colonialidade do gênero". Chamo a possibilidade de superar a colonialidade do gênero de "feminismo descolonial".

O feminismo descolonial tem sido também pensado pela antropóloga feminista Rita SEGATO (2012). A autora sustenta uma "pré-história patriarcal da humanidade" e um dualismo

${ }^{4} \mathrm{~A}$ autora defende que "o sistema de gênero é não só hierárquico, mas racialmente diferenciado, e a diferenciação racial nega humanidade e, portanto, gênero às colonizadas. Irene Silverblatt, Carolyn Dean, Maria Esther Pozo e Johnni Ledezma, Pamela Calla e Nina Laurie, Sylvia Marcos, Paula Gunn Allen, Leslie Marmon Silko, Felipe Guaman Poma de Ayala e Oyeronke Oyewumi, entre outros, permitem-me afirmar que o gênero é uma imposição colonial" (LUGONES, 2014, p. 942). 
não binário, mas complementar de gênero no mundo indígena que é erodido pela colonização:

A posição masculina ancestral, portanto, se vê agora transformada por este papel relacional com as poderosas agências produtoras e reprodutoras da colonialidade. É com os homens que os colonizadores guerrearam e negociaram, e é com os homens que o Estado da colonial/modernidade também o faz (SEGATO, 2012, p. 119).

A antropóloga possui experiência em diferentes trabalhos de campo e programas de cooperação internacional sobre gênero que não deram certo:

A proposta de transversalizar políticas de gênero está alicerçada sobre a ideia errônea, examinada acima, de que na aldeia o espaço público, como na colonial/modernidade, tem valor universal, e o doméstico, como no regime colonial/moderno, é de interesse particular, privado e íntimo, estabelecendo uma hierarquia entre ambos (SEGATO, 2012, p. 125).

No que se refere às relações entre gênero, colonialidade e modernidade, Segato (2012) sustenta três principais visões. A primeira seria a do "feminismo eurocêntrico" que compreende a universalidade da dominação patriarcal e de gênero, procurando orientar as "outras" mulheres sobre a importância da unidade e do avanço da modernidade no campo dos direitos. Na outra ponta, as análises de Lugones e Oyewùmi, que entendem o gênero como uma imposição colonial. Por fim, uma terceira linha, na qual a própria autora inclui-se, fundamentada em pesquisas etnográficas e evidências históricas, apoia-se na comprovação de maneira incontestável da existência de um "patriarcado de baixa intensidade" nas sociedades tribais afro-americanas e indígenas. Essa percepção é compartilhada pelo feminismo comunitário da aymara lésbica Julieta Paredes. Poderíamos incorporar a esta terceira visão, que nos parece a mais razoável, a observação não excludente de que "colonialism eroded many matriline alor woman-friendly cultures and practices, or intensified women's subordination in colonised lands" (LOOMBA, 2005, p. 141).

A tensa relação entre sexualidade e colonialidade também se desdobra de diferentes maneiras. Para autoras como Lugones e Segato, é compreensível que pessoas transgênero não possam encontrar seu lugar no mundo moderno/colonial. Por outro lado, teorizações queer podem parecer problemáticas do ponto de vista dos feminismos não individualizantes e liberais (Nxu ZÄNÄ, 2010).

As apostas teóricas em um feminismo descolonial têm sido, por enquanto, autorais de acadêmicas feministas com atuação e trajetória nos movimentos e lutas das mulheres. ${ }^{5}$ Aproximando a abordagem da ideia de "feminismos do sul" (Marlise MATOS, 2010; BIDASECA, 2014a), o "feminismo branco" passa a ser visto com desconfiança, conforme a adaptação contemporânea e latino-americana de Bidaseca (2011) da frase de Spivak:6 "mujeres blancas buscando salvar a las mujeres color café de los hombres color café".

É preciso notar que o feminismo latino-americano possui uma larga história de encontros e construções dos movimentos feministas e de mulheres, independentemente de suas rotulações conceituais e acadêmicas. Rosa Cobo BEDIA (2014), em um texto simples e sensato, nos diz que

\footnotetext{
${ }^{5}$ Ver, também, a coletânea organizada por Yuderkys Espinosa MIÑOSO, Diana Gómez CORREAL, Karina Ochoa MUÑOZ, Karina Ochoa (2014). Muitas de suas publicações relevantes ocorrem por editoras alternativas e não comerciais ou acadêmicas. Tradução feminista é um assunto fundamental para nossos tempos (cf. LIMA COSTA \& ALVAREZ, 2013).

${ }^{\circ}$ Sobre a intervenção colonial britânica no ritual sati: "homens brancos estão salvando mulheres de pele escura de homens de pele escura" (SPIVAK, 2012, p. 119).
} 
no parece adecuado hablar de feminismo latinoamericano, de la misma forma que la definición de feminismo europeo o africano no nos devuelve una realidad homogénea. No es correcto hablar de feminismo del Norte ni de feminismo del Sur, como tampoco de feminismo latinoamericano o feminismo europeo como si fuese una realidad holística e hiper coherente. En este momento histórico en el que las tecnologías in formación al es hacen posible que las ideas circulen aceleradamente, se observa que en todos los continentes existen debates que son comunes. Las múltiples opresiones contra las mujeres se repiten en casi todas las sociedades del mundo (p. 40).

Para a autora, é mais conveniente falarmos em "debates feministas na América Latina" (2014). É claro que existem muitas tendências e disputas nesse contexto. As características compartilhadas pela América Latina, Centro-América e Caribe como região não implicam uma vivência e um passado comumente sentidos por todas as mulheres "Iatino-americanas". Aqui estamos falando de desigualdades e injustiças, amarradas historicamente em estruturas políticas, sociais, culturais e econômicas, para pensarmos as múltiplas identidades, necessidades, reivindicações e interesses feministas. O triângulo da desigualdade, pobreza e violência na América Latina, identificado pelo PNUD (Programa das Nações Unidas para o Desenvolvimento) (2004), por exemplo, eleva o continente com os níveis mais altos de desigualdade e de violência do mundo. Mediante tal contexto extremamente atual, uma diferente gama no âmbito da conquista e da garantia de direitos individuais e sociais (coletivos, culturais e naturais) é constantemente ameaçada e violada - pelo Estado, pelo mercado e pela sociedade.

Nota-se que a crescente transnacionalização e a internacionalização do movimento feminista vieram também acompanhadas de sua "onguização". De maneira geral, o controverso conceito de sociedade civil global pôde ser criticado pela não horizontalidade dialógica de suas agendas e pelo protagonismo do Norte em formulá-las e implementálas no Sul. Seu associativismo ativista pode ser extremamente elitizado e profissionalizado. De acordo com Yuderkys Espinosa MIÑOSO (2009), os anos noventa foram críticos para o feminismo latino-americano pela tensão gerada entre as "institucionalizadas" e as "autônomas". Sua crítica é dura:

Lo que en el Norte puede ser celebrado con buenos ojos (ojos de occidente) tuvo consecuencias nefastas para el movimiento feminista en América Latina. La solidaridad feminista sin fronteras ha sido un espacio usufructuado por unas pocas privilegiadas del Sur que gracias a sus pertenencias de clase, origen, color o gracias a su acceso a fuentes de financiamiento, han obtenido prestigio y mejor ad ele status individual. El surgimiento de este nuevo campo desterritorializado del activismo ha significado una desconexión real de los liderazgos feministas de sus bases, ha implicado un processo de especialización, profesionalización y tecnocratización del feminismo con sus secuelas de fragmentación y sectorización de las luchas y del movimiento. Implicó la consolidación de una elite feminista que en alianza con las feministas del primer mundo determinan en espacios accesibles solo para unas pocas, los lineamientos del movimiento (p. 51).

E prossegue na denúncia da subalternidade pelo feminismo hegemônico:

Si la afrodescendente o la indígena o mestiza, madre o lesbiana, trabajadora precarizada, campesina o fuera del mercado laboral, estudiante o analfabeta, monolingüe, bilingüe, expulsada por la pobreza o por la guerra a países del primer mundo... si ellas son nombradas, si ellas son objeto de discursos y políticas, aunque las feministas "comprometidas" del Sur y del Norte "hablen por ella"... ella definitivamente no está ahí. 
O movimento feminista reproduz no âmbito interno várias dicotomias problemáticas intensificadas pela globalização: local $x$ global, particular $x$ universal, pós-colonialismo $x$ cosmopolitismo. As tentativas de cosmopolitização da agenda feminista são associadas com universalismo, etnocentrismo, eurocentrismo e ocidentalismo pelos feminismos subalternos. Nestes termos, a construção de uma agenda feminista justa, inclusiva e democrática depara-se com incentivos e constrangimentos, com oportunidades e obstáculos. A criação de novos espaços, fóruns, encontros e diálogos para a criação e luta feminista no âmbito internacional (sistema ONU) e ambiente virtual, ao mesmo tempo, despertou questionamentos quanto à possibilidade de solidariedade transnacional e global sisterhood. Estes questionamentos são feitos pelos feminismos subalternos.

A ideia de global sisterhood (conceito de Robin Morgan) como marca fundante do feminismo global apoiou-se na universalidade do patriarcado como experiência de opressão comum de todas as mulheres, independentemente de raça, classe, sexualidade e nacionalidade (MENDOZA, 2014). Mas, e se a universalidade do patriarcado for colocada em xeque? E se a diferença de classe - aquela que não é louvada - nada significar para um contingente de mulheres? Os feminismos subalternos instigam que nem sempre as mulheres são aliadas e alinhadas entre si em suas disputas e conflitos pela justiça. Quando os próprios Direitos Humanos são questionados pelo seu eurocentrismo, a argumentação das feministas ocidentais pelo entendimento dos direitos das mulheres como direitos humanos ainda é mais acentuada.

Mas, nem tudo é fragmentação, desunião e desagregação. Existem espaços de confluência, colaboração, síntese e criação alternativas. Neste contexto, "tradução" se transforma em uma palavra mágica. Não se trata de um debate sobre diferenças, mas, sim, sobre estar em diferentes posições para enxergá-las, ou, mesmo, identificá-las. O debate ainda é sobre igualdade.

\section{Referências}

AHMAD, Aijaz. Linhagens do Presente. São Paulo: Boitempo, 2002.

ALATAS, Syed Farid. "Academic dependency and the global division of labour in the social sciences". Current Sociology, v. 51, n. 6, p. 599-613, nov. 2003.

ALMEIDA, Sandra Regina Goulart. "Intervenções feministas: pós-colonialismo, poder e subalternidade". Revista Estudos Feministas, Florianópolis, v. 21, n. 2, p. 689-700, nov. 2013.

ASHCROFT, Bill; GRIFFITHS, Gareth; TIFFIN, Hellen. The empire writes back: theory and practice in post-colonial literature. London/New York: Routledge, 2002 [1989].

BAHRI, Deepika. "Feminismo e/no pós-colonialismo". Revista Estudos Feministas, Florianópolis, v. 21, n. 2, p. 659-688, nov. 2013.

BAKARE-YUSUF, Bibi. "'Yorubas don't do gender": a critical review of Oyeronke Oyewumi's The Invention of Women: making an African sense of western gender discourses". African Identities, v. 1, n. 1, p. 122-142, 2003.

BALLESTRIN, Luciana. "América Latina e o giro decolonial". Revista Brasileira de Ciência Política, n. 11, p. 89-117, mai./ago. 2013.

BEDIA, Rosa Cobo. "Aproximaciones a la teoria crítica feminista". Boletín del Programa de Formación, Lima, CLADEM, n. 1, 2014.

BHAMBRA, Gurminder K. "As possibilidades quanto à sociologia global: uma perspectiva pós-colonial". Revista Sociedade e Estado, v. 29, n. 1, p. 131-151, jan./abr. 2014.

BIDASECA, Karina. "'Mujeres blancas buscando salvar a mujeres color café': desigualdad, colonialismo jurídico y feminismo postcolonial". Andamios. Revista de Investigación Social, v. 8, n. 17, p. 61-89, set./dez. 2011. 
"Los peregrinajes de los feminismos de color en el pensamiento de María Lugones". Revista Estudos Feministas, v. 22, n. 3, p. 953-964, set./dez. 2014a.

"Reconociendo las superfícies de nuestras hendiduras. Cartografiando el Sur de nuestros Feminismos". In: ; OTO, Alejandro José de; OBARRIO, Juan; SIERRA, Marta (Comps.). Legados, genealogias y memórias poscoloniales en América Latina: escritas fronterizas desde el Sur. Buenos Aires: Godot, 2014b. p. 243-244.

BUTLER, Judith. Problemas de gênero: feminismo e subversão da identidade. Rio de Janeiro: Civilização Brasileira, 2015.

CONNELL, Raewyn. Southern Theory. Cambridge: Polity Press, 2007.

"Social Science on a world scale: connecting the pages". Sociologies in dialogue, Porto Alegre, v. 1, n. 1, p. 1-16, jul.-dez. 2015.

DIRLIK, Arif. "The Postcolonial Aura: third world criticism in the age of global capitalism". Critical Inquiry, v. 20, n. 2, p. 328-356, 1994.

ESCOBAR, Arturo. "Mundos y conocimientos de otro modo: el programa de investigación modernidad/colonialidad Latino Americano". Tabula Rasa, n. 1, p. 58-86, jan.-dez. 2003.

FANON, Frantz. Peles negras, máscaras brancas. Salvador: EDUFBA, 2008 [1952].

FRASER, Nancy. "Mapeando a imaginação feminista: da redistribuição ao reconhecimento à representação". Revista Estudos Feministas, Florianópolis, v. 15, n. 2, p. 291-308, mai./ ago. 2007.

GANDHI, Leela. Postcolonial Theory: a critical introduction. Austrália: Allen \& Unwin, 1998.

GROSFOGUEL, Ramón. "Para descolonizar os estudos de economia política e os estudos pós-coloniais: transmodernidade, pensamento de fronteira e colonialidade global". Revista Crítica de Ciências Sociais, n. 80, p. 115-147, mar. 2008.

LIMA COSTA, Claudia de; ALVAREZ, Sonia. "A circulação das teorias feministas e os desafios da tradução". Revista Estudos Feministas, v. 21, n. 2, p. 579-586, mai./ago., 2013.

LIMA COSTA, Claudia de. "Equivocação, tradução e interseccionalidade performativa: observações sobre ética e prática feministas descoloniais". In: BIDASECA, Karina; OTO, Alejandro de; OBARRIO, Juan; SIERRA, Marta (Comps.). Legados, genealogias y memórias poscoloniales en América Latina: escritas fronterizas desde el Sur. Buenos Aires: Godot, 2014. p. 273-306.

LUGONES, María. "Colonialidad y género". Tabula Rasa, n. 9, p. 73-101, jul./dez. 2008.

"Rumo a um feminismo descolonial". Revista Estudos Feministas, v. 22, n. 3, p. 935952, set./dez. 2014

LOOMBA, Ania. Colonialism/Postcolonialism: the new critical idiom. New York: Routledge, 2005.

MALDONADO-TORRES, Nelson. "Sobre la colonialidad del ser: contribuciones al desarrollo de un concepto". In: CASTRO-GÓMEZ, Santiago \& GROSFOGUEL, Ramon (Coords.). El giro decolonial: reflexiones para una diversidad epistémica más allá del capitalismo global. Bogotá: Siglo del Hombre Editores; Universidad Central, Instituto de Estudios Sociales Contemporáneos e Pontificia Universidad Javeriana, Instituto Pensar, 2007. p. 157-168.

MATOS, Marlise. "Movimento e teoria feminista: é possível reconstruir a teoria feminista a partir do sul global?". Revista de Sociologia e Política, Curitiba, v. 18, n. 36, p. 67-92, jun. 2010.

McCLINTOCK, Anne. "The Angel of Progress: pitfalls of the term post-colonialism". Social Text, n. 31/32, Third World and Post-Colonial Issues, p. 84-98, 1992.

MELLINO, Miguel. La crítica pós-colonial: descolonización, capitalismo y cosmopolitismo en los estudios poscoloniales. Buenos Aires: Paidós, 2008.

MENDOZA, Breny. "Transnational feminism in question". Feminist Theory, v. 3, n. 3, p. 295-314, 2009. 
MIÑOSO, Yuderkys Espinosa. "Ełnocentrismo y colonialidad en los feminismos latinoamericanos: complicidades y consolidación de las hegemonias feministas en el espacio transnacional". Revista Venezolana de Estudios de la Mujer, v. 14. n. 33, p. 37-54, jul.dez. 2009.

; CORREAL, Diana Gómez; MUÑOZ, Karina Ochoa. Tejiendo de otro modo: Feminismo, epistemología y apuestas descoloniales en Abya Yala. Popayán: Editorial Universidad del Cauca, 2014

MIGNOLO, Walter. Historias locales/disenosglobales: colonialidad, conocimientos subalternos y pensamiento fronterizo. Madrid: Akal, 2003.

La idea de América Latina. La herida colonial y la opción decolonial. Barcelona: Gedisa Editorial, 2005.

MOHANTY, Chandra Talpade. "Bajo los ojos de Ocidente: feminismos académicos y discursos coloniales". In: NAVAZ, Liliana; CASTILLO, Rosalva (Eds.). Descolonizando el feminismo: teorías y prácticas desde los márgenes, 2008 (1984). Disponível em: http://webs.uvigo.es/ pmayobre/textos/varios/descolonizando.pdf.

"De vuelta a "Bajo los ojos de Occidente": la solidaridad feminista a través de las luchas anticapitalistas". In: NAVAZ, Liliana; CASTILLO, Rosalva (Eds.). Descolonizando el feminismo: teorías y prácticas desde los márgenes, 2008a. Disponível em: http:// webs.uvigo.es/pmayobre/textos/varios/descolonizando.pdf.

NAVAZ, Liliana Suárez; CASTILLO, Rosalva Aída Hernández (Eds.). Descolonizando el feminismo: teorías y prácticas desde los márgenes, 2008 (1984). Disponível em: http:// webs.uvigo.es/pmayobre/textos/varios/descolonizando.pdf.

PINTO, Céli Regina Jardim. "Feminismo, história e poder". Revista de Sociologia e Política, Curitiba, v. 18, n. 36, p. 15-23, jun. 2010.

PNUD. Programa das Nações Unidas para o Desenvolvimento. A democracia na América Latina: rumo a uma democracia de cidadãs e cidadãos, 2004. Disponível em: http:// www.pnud.org.br/pdf/TextoProddal.pdf. Acesso em: 08/2015.

QUIJANO, Aníbal. "Colonialidad del poder y clasificación social". Journal of world-systems research, v. 11, n. 2, p. 342-386, 2000

SAID, Edward. Orientalismo. São Paulo: Cia das Letras, 2007 [1978].

SEGATO, Rita Laura. "Gênero e colonialidade: em busca de chaves de leitura e de um vocabulário estratégico descolonial”. E-cadernos ces, n. 18, 2012. Disponível em: http:/ /eces.revues.org/1533. Acesso em: 07/2015.

SPIVAK, Gayatri. Pode o subalterno falar? Belo Horizonte: EDUFMG, 2010 [1988].name>

ZÄNÄ, Nxu. Contra la teoria queer, 2010. Disponível em: http://www.ciudaddemujeres.com/ articulos/. Acesso em: 10/2014.

[Recebido em 07/01/2016, reapresentado em 13/12/2016 e aprovado em 16/02/2017]

\section{Subaltern Feminisms}

Abstract: Especially from the 1980s, the encounter between postcolonialism and feminism brought important theoretical and practical implications for understanding the lives of women under the impact - past or present - of colonialism. One of the most obvious was the geopolitization of the feminist debate, inaugurated by the idea of a Third World feminism and post-colonial, and currently, can be seen in the attempt to project a feminism Southern and decolonial. This paper has two main theoretical objectives: (a) To demonstrate the antagonism built since the 1980s between non-Western and Western feminisms and (b) To develop a critical dialogue with 
contemporary version of decolonial Latin American feminism in relation to the notion of gender coloniality. I propose the term "subaltern feminisms" to the understanding of a paradoxical movement: the construction of others feminisms is only possible when they subalternalize in relation to the modern feminism. As a result, highlights the tension between fragmentation limit of irreconcilable differences and the necessary cosmopolitization of the feminist agenda.

Keywords: Postcolonial feminism; Decolonial Feminism; Coloniality; Gender

Luciana Maria de Aragão Ballestrin (luballestra@gmail.com) é professora de Ciência Política no Curso de Relações Internacionais e no Programa de Pós-Graduação em Ciência Política da Universidade Federal de Pelotas. Pesquisa e publica nas áreas de teoria política contemporânea, democrática, pós-colonial e decolonial. Coordena o grupo de pesquisa Subalternidades Globais (UFPel).

1054 Estudos Feministas, Florianópolis, 25(3): 1035-1054, setembro-dezembro/2017 